Al-Ahmady: Effect of airflow rate and submergence of diffusers on oxygen.....

\title{
EFFECT OF AIRFLOW RATE AND SUBMERGENCE OF DIFFUSERS ON OXYGEN TRANSFER CAPACITY OF DIFFUSED AERATION SYSTEMS
}

\author{
Dr. Kossay K. Al-Ahmady \\ University of Mosul, College of Engineering, Civil Engineering \\ Department
}

\begin{abstract}
Oxygen transfer capacity has greatest influence on activated sludge performance. In this study, experimental procedure is carried out to determine the effect of airflow rate and the level of diffusers submergence, on the oxygen transfer rate of diffused air systems. In addition, a number of readings were also collected from published papers. The data were selected to cover various scales of plants and operating conditions. After sorting out, all data were treated and then combined to the experimental readings in order to expand the applicability of the results. Individual mathematical models to describe the effect of each parameter were also derived. The results of the study showed that, increasing the airflow rate at fixed water depth and diffusers submergence enlarge the oxygenation capacity of the system. The equation, which controls this relationship, is linear. At diffusers submergence of $4.6 \mathrm{~m}$, the slope of the equation was 11.8. With reduce the depth of diffusers to about $0.4 \mathrm{~m}$; the slope of equation was decrease to 2.3. At constant airflow rate, the depth of diffusers has a significant effect on both of the oxygenation capacity and oxygen transfer efficiency of the system. Exponentional form of equation is shown to be efficient in expressing the relationship between the submergence and the oxygenation capacity. At $0.4 \mathrm{~m}$, diffusers submergence, the oxygen transfer efficiency was 1.8 whereas; this value is rising to about 11.5 at $4.6 \mathrm{~m}$ submergence.
\end{abstract}

Keywords :Oxygen transfer capacity, diffused aeration, airflow rate, diffusers submergence, $K_{L} a$

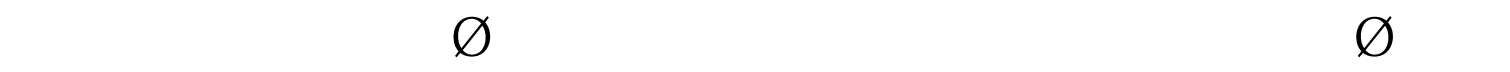

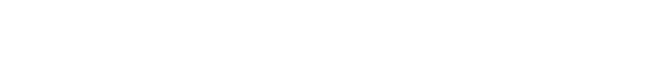

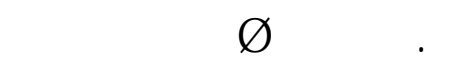

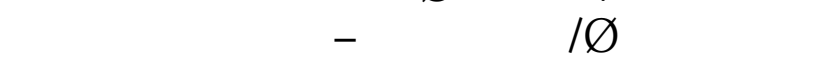

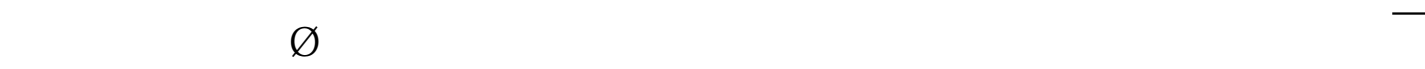

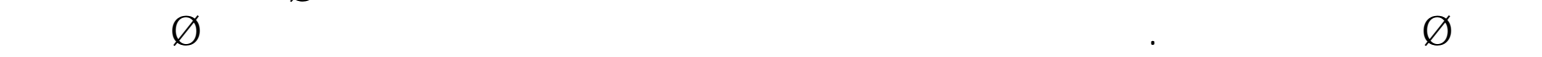

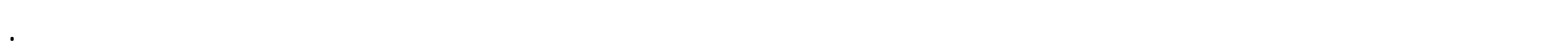

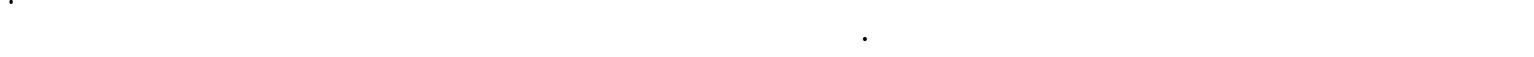

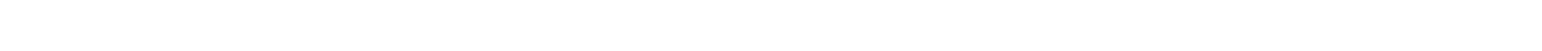

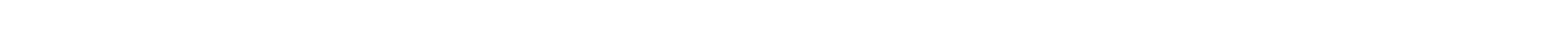

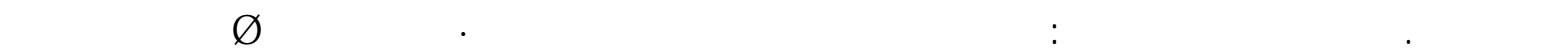

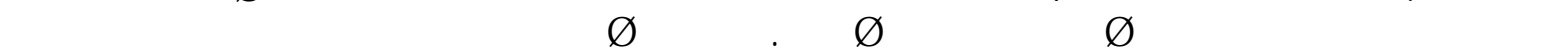

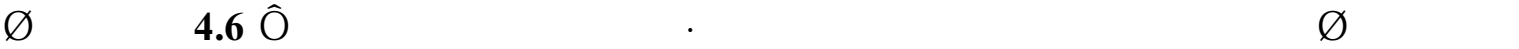
RÝs Bक.

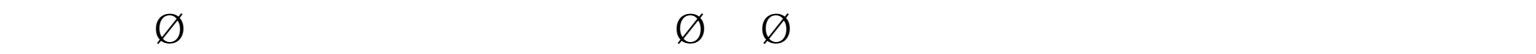

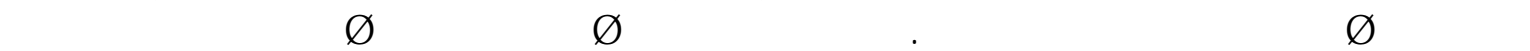

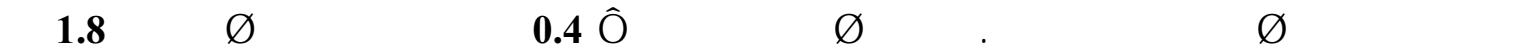

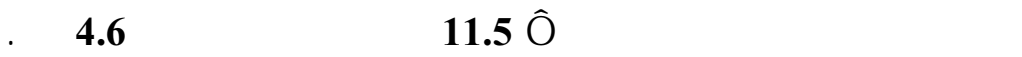

Received $1^{\text {st }}$ Feb. $2005 \quad$ Accepted ${ }^{\text {th }}$ April 2005




\section{$\begin{array}{llll}\text { Al-Rafidain engineering } & \text { Vo. } 14 & \text { No. } 1 & 2006\end{array}$}

\section{Introduction}

Among the many complex design decisions to be made when designing an activated sludge process or aerobic sludge stabilization, the sizing of aeration tanks and aeration systems that have the greatest influence on the oxygen transfer efficiency and the degree of dispersion, which ultimately determine the overall efficiency and economics of the treatment process. Oxygen transfer is a function of mass transfer across a gas liquid interface. Examination of diffused air aeration shows that the oxygen is transferred at both time of bubble formation and after the bubble leaves the diffuser. The bulk of transfer occurs after the bubble has left the diffuser as is evident by linear increase in transfer efficiency versus depth. Both oxygen transfer and the degree of mixing in the aeration tanks depend on certain hydrodynamic and physiochemical factors. Factors affecting oxygen transfer rate (percent oxygen fed through the diffuser and absorbed by the liquid) are; geometric characteristics of the system, such as, tank dimensions, and aeration device parameters; size and location and the system dynamic characteristics, of which most important is the air feed rate $[8]$.

Other factors such as surface tension that tend to break up larger bubble are important, but the concept of smaller bubbles having larger interfacial area and better efficiency remains.

In this paper the effect of each of these parameters on both of the oxygen transfer capacity (OC) and oxygenation efficiency (E) (the amount of oxygen transferred to the bulk solution of the system by passing one meter cubic of air throughout the water) systems were studied.

\section{Research Objectives}

This research aim to achieve the following objectives:

1. To determine the effect of diffuser submergence, (h) on oxygen transfer capacity (OC) of the system,

2. To evaluate the effect of diffuser air loading rate (D) on the on oxygen transfer capacity $(O C)$ of the system,

3. To determine the effect of these two parameters on the transfer efficiency of the oxygen to the system,

4. To suggest some equations that control the effect of these parameters on both of the oxygen transfer capacity and oxygenation efficiency of the system.

\section{Oxygen Transfer}

Oxygen transfer is described by values of the mass transfer coefficient and the equilibrium concentration of oxygen in the liquid. The best-known explanation for the mechanism of gas transfer to a liquid is given by the two-film theory. According to this theory, it is the presence of two films, one liquid and one gas, at the gas-liquid interface which provides the resistance to the passage of gas molecules from the bulk of gas phase to that of liquid phase.

For gases of high solubility in the liquid phase, e.g., absorption of $\mathrm{SO}_{2}$ by water, the major resistance to the absorption is that offered by the gas film. For gases of low solubility in the liquid phase, e.g., absorption of oxygen by aqueous liquor, the controlling resistance resides in the liquid film [7]. 
Al-Ahmady: Effect of airflow rate and submergence of diffusers on oxygen.....

The process of oxygen transfer from a gaseous to an aqueous phase occurs in three steps [16]:

1. Saturation of the liquid surface between the two phases. This rate of oxygen transfer is very rapid since the resistance of the gas film is negligible and thus this step is never the controlling one.

2. Passage of the oxygen molecules through the liquid interface film by molecular diffusion. At very low mixing levels, the rate of oxygen operation is controlled by step 2. At higher turbulence levels, the interface film is broken up and the rate of renewal of the film controls the absorption of the oxygen. Surface renewal rate is frequently at which liquid with an oxygen concentration (C) (oxygen concentration in the bulk of the liquid phase) replaces that from the interface with an oxygen concentration equal to $C_{s}$ (saturation concentration of oxygen).

3. Oxygen is transferred to the bulk of the liquid by diffusion and convection.

Oxygen Transfer coefficient

There are several methods of experimental determination of mass transfer coefficients. The so-called clean water non-steady state method was selected in this study. The unsteady state test or reaeration of deoxygenated clean water (reoxygenation) is presently the most broadly accepted test procedure [8]. This method involves (1) the initial deoxygenating of the clean water in the test aeration basin, (2) recording of the oxygen concentration increase while aerating the previously deoxygenated water. Because the value of oxygen transfer coefficient $\left(K_{L}\right)$ is only dependent on the hydrodynamic properties of the system it makes no difference to aerate with air or with oxygen [8]. Relationships that describe the rate of water oxygenating in step (2), and formulae for computing the oxygen mass transfer coefficient are presented in the following.

$$
\frac{d c}{d t}=K_{\mathrm{L}} \cdot \frac{A}{V} \cdot\left(C_{S}-C\right)
$$

Where:

$K_{L}$ : oxygen transfer rate across the gas liquid film, $(\mathrm{m} / \mathrm{s})$

$C$ : oxygen concentration at time $(\mathrm{t}),(\mathrm{mg} / \mathrm{L})$

$C_{s}$ : the saturation concentration of oxygen in water and, $(\mathrm{mg} / \mathrm{L})$

$A:$ the interfacial area for transfer, $\left(\mathrm{m}^{2}\right)$

$V$ : liquid volume, $\left(\mathrm{m}^{3}\right)$

$t$ : the time, (sec)

$d c / d t$ : the rate of change of the oxygen concentration.

In the determination of the mass-transfer coefficient, the term $\left(K_{L} \cdot V / A\right)$ is usually rewritten as overall coefficient $K_{\mathrm{L}}$ a without attempting to separate the factors $K_{L}$ and $(V / A)$.

Where:

$$
a=\frac{A}{V} \quad \text { The interfacial area per unit volume, } \mathbf{m}^{2} / \mathbf{m}^{3}
$$




\section{Al-Rafidain engineering $\quad$ Vo.14 No. $1 \quad 2006$}

The difference $\left(\mathrm{C}_{\mathrm{s}}-\mathrm{C}\right)$ between saturation value and actual concentration of oxygen $(C)$ in the body of the liquid phase is usually called oxygen deficit. Integration of this equation (with $\mathrm{C}=\mathrm{Co}$ at $\mathrm{t}=\mathbf{0}$ ) leads to:

$$
\operatorname{In}\left(C_{s}-C\right)=-K_{L a} . t+\operatorname{In}\left(C_{s}-C o\right)
$$

A plot of In $\left(C_{s}-C\right)$ against $t$ resulted in a straight line with a slope of $K_{L} . S$.

The overall reaeration constant $K_{L}$ a can be obtained experimentally by aerating water unsaturated with oxygen and observing the change in the dissolved oxygen deficit versus time $[1,8]$. Aeration efficiency of the system always expressed in term of oxygen transfer capacity $O C$ that represent the capability of system to transfer oxygen in $\mathrm{g} / \mathrm{m}^{3} . \mathrm{h}$, then;

$$
O C=K_{L} a \cdot C_{S}
$$

Where:

$O C$ : oxygen transfer capcity at $20 \mathrm{C}$,

\section{Experimental Work}

The experimental work was designed to determine the correlations between oxygen absorption efficiency and the hydraulic property of air-water mixture. Reoxygenation may be accomplished by the addition of sodium sulfite and cobalt catalyst, or by nitrogen stripping $[1,8,16]$. Since stripping with nitrogen gas is impractical in large scale testing $[1,2,4]$, sodium sulfite with cobalt is used almost exclusively. Many papers have addressed problems associated with the use of cobalt as catalyst, and the method used to measure DO $[5,7,8,16]$. In this

paper, the oxygen transfer tests were conducted with a batch mode operation, using potable water. The tests were carried out in tanks $(0.55 \times 0.35 \times 0.38 \mathrm{~m})$ and $(1.0 \times 0.5 \times$ $1.0 \mathrm{~m}$ ), (Length $\mathrm{x}$ Width $\mathrm{x}$ Depth), and system parameters were varied over a wide range so that the results of the study could be used for a board range of study. The experiments were divided into groups. In each group, the effect of diffuser air loading (D) and, the diffuser submerge (h) on both of the oxygen transfer capacity (OC) and on the oxygenation efficiency (E) were investigated. Prior to tests, the models were drained, cleaned and filled with clean water. The liquid in the tank was changed after every 3-5 runs to avoid salt accumulation $[6,16]$. The air flowrate was measured with a pre-calibrated meter. Dissolved oxygen and temperature were monitored as aeration proceeds.

Oxygen was depleted from water by using sodium sulfite as a reducing agent. The sodium sulfite $\left(\mathrm{Na}_{2} \mathrm{SO}_{3}\right)$ was added to the model as a stock solution. The total amount of $\left(\mathrm{Na}_{2} \mathrm{SO}_{3}\right)$ required per run were calculated as:

$$
\mathrm{Na}_{2} \mathrm{SO}_{3}+1 / 2 \mathrm{O}_{2} \rightarrow \mathrm{Na}_{2} \mathrm{SO}_{4}
$$

The stoichiometric ratio is

$$
\frac{\mathrm{Na}_{2} \mathrm{SO}_{3}}{1 / 2 \mathrm{O}_{2}}=\frac{126}{16}=7.9
$$


Al-Ahmady: Effect of airflow rate and submergence of diffusers on oxygen.....

This means that theoretically $(7.9 \mathrm{ppm})$, of $\left(\mathrm{Na}_{2} \mathrm{SO}_{3}\right)$ are required to remove (1ppm) dissolved oxygen. Based on the dissolved oxygen of the test tap water, the approximate $\left(\mathrm{Na}_{2} \mathrm{SO}_{3}\right)$ requirements were estimated. $10-30 \%$ excess was used according to [8]. The amounts of $\left(\mathrm{Na}_{2} \mathrm{SO}_{3}\right)$ were added to a separate basin containing water. The sodium sulfite was maintained in suspension by mixing. Sufficient cobalt chloride is added to provide a minimum $\mathrm{Co}^{+2}$ concentration of $1.5 \mathrm{ppm}$ [5].

Dissolved oxygen determinations were made on samples collected at point located near the side of basin. Because of the volume of basin is small, one sample location was assumed to be representative the total basin volume [16]. In some runs, the readings were conducted with another positions but no difference was noted.

The oxygen concentrations were read using a properly calibrated dissolved meter type (EXTECH; model 407510).

Water temperature was measured before and after each test, and the average values were used in data analysis. It was not possible to conduct all tests at $20 \mathrm{C}$ as has been recommended $[1,16]$, therefore, the values of $K_{L}$ a obtained had to be adjusted to the standard temperature of $20 \mathrm{C}$ according to the equation:

$\mathbf{K}_{\mathbf{L}} \mathbf{a}=\mathbf{K}_{\mathbf{L}} \mathbf{a}_{(20)} \times \theta^{(\mathbf{T}-20)}$

Where:

$T$ : is the temperature $(C) ; \theta=1.024$ [8]

The major shortage in this testing that it is carried out in small scale so, its results mainly limit by the testing circumstances [8]. Accordingly, in this paper a large amount of actual data were also collected from published papers $[3,6,7,11-15]$. The data is selected to cover various scales of plant and operating conditions (water depth from 1.4 to $6.0 \mathrm{~m}$, diffuser submergence ranged from 12 to $97 \%$, diffuser air loading up to $360 \mathrm{~m}^{3}$ air/m $\mathrm{m}^{3}$ tank. hr) $[3,6,7,11-15]$. After sorting out all data were treated and analyzed to evaluate the effect of the selected parameters on both of the oxygen transfer capacity the yield oxygen transfer rate. Individual mathematical models to describe the effect of each parameter were also derived.

\section{Results and discussion}

In figure 1, the oxygen transfer capacity of the systems is represented as a function of airflow rates at different ranges of operation conditions. As shows in the figure, there is distinguish and direct proportional between the airflow rate and the oxygenation capacity of the system under all conditions of operation.

These relationships can be good represented by the linear correlations, which exposed in the figure. The slopes of the curves are increase with increasing the aerator submerges. At $0.4 \mathrm{~m}$ submergence, the slope of the curve was 2.32 whereas this slope is increases to about 11.8 at the $4.6 \mathrm{~m}$ submergence. Fig 2 shows the effect of airflow rates on the oxygenation capacity of the system at different $(\mathrm{h} / \mathrm{H})$ values that represent the ratios of aerator submerges to the depth of water in the tank. As noted in the figure, this ratio plays a great rule on the oxygenation capacity of the system. Increasing the ratio of submerges of the diffuser to water depth from about 0.12 to 0.96 (i.e. 8 times), raise the slope of the curve to 31.2 (i.e. more than 10 times). However, this figure is a modified form of figure 1 but it gives a conclusion 


\section{Al-Rafidain engineering Vo.14 No. $1 \quad 2006$}

to the necessity of setting the diffusers headers at the bottom of the tank to achieve a maximum influence of airflow rate. In table 1, some of the experimental results were also represented.

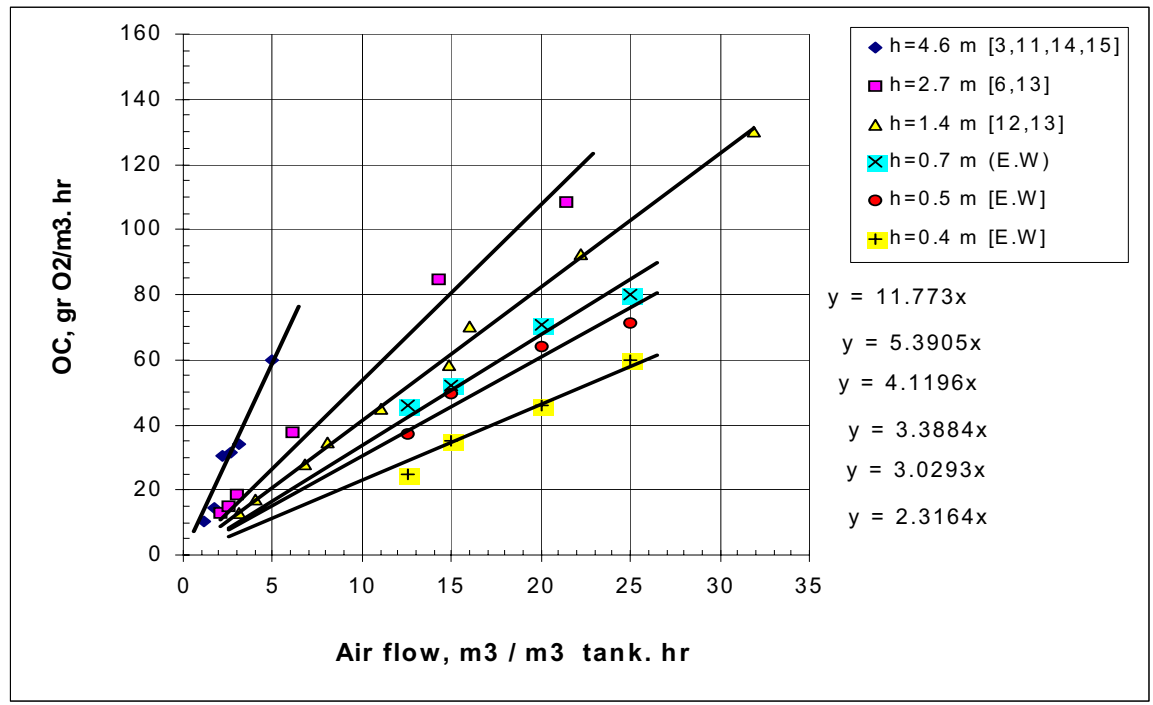

Fig (1): Effect of airflow rate (D) on oxygenation capacity (OC) of the system at various

levels of aerator submergence (h). E.W: experimental work

However, the effect of airflow rate on the oxygenation capacity can be explained by the mechanism of exchange of the oxygen from the gas to liquid. During this phase, the transfer is occurring by the processes of: bubble formation, release, and ascension. This rate of oxygen transfer is dependent on the relative rate of ascent, bubble size, partial pressure of oxygen, temperature, and driving force (the difference between the liquid-film oxygen concentration in equilibrium with the gas bubble and the bulkliquid dissolved oxygen content). Additionally, the

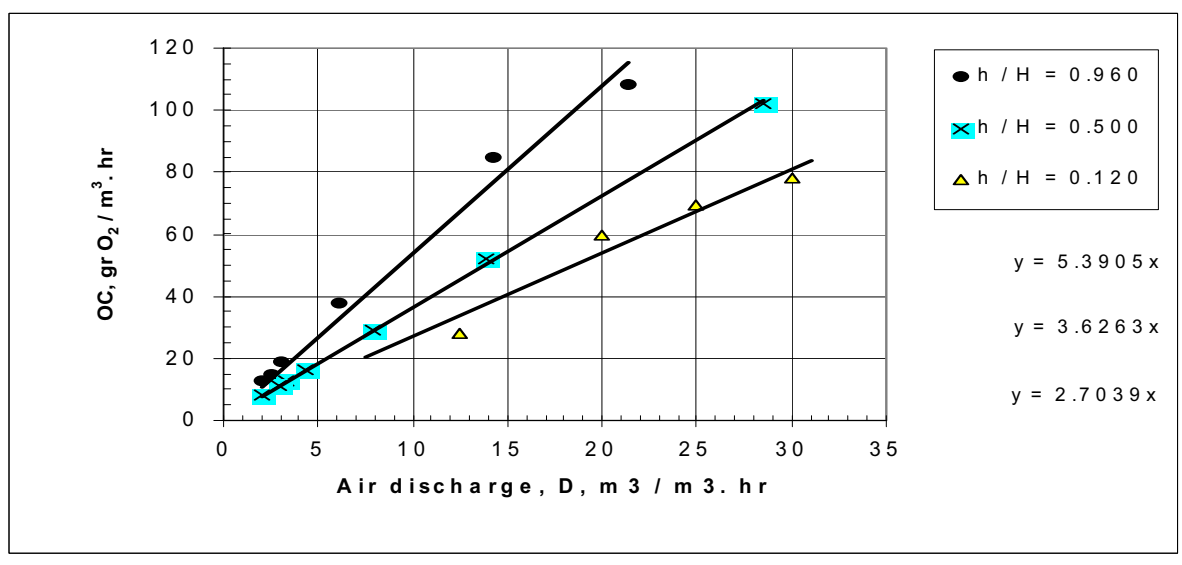

Fig (2): Effect of specific airflow rate (D) on oxygenation capacity (OC) of the system under different $(\mathrm{h} / \mathrm{H})$ ratios. $[6,11-13]$ 
Al-Ahmady: Effect of airflow rate and submergence of diffusers on oxygen.....

Table 1: results of some of the experimental work

\begin{tabular}{|c|c|c|c|c|c|}
\hline \multicolumn{3}{|c|}{ Tank size } & $\begin{array}{c}\text { diffusers } \\
\text { Submerges }\end{array}$ & $\begin{array}{c}\text { Air flowrate, (D) } \\
\text { m3/m3.hr }\end{array}$ & $\begin{array}{c}\text { Oxygenation } \\
\text { Capacity (OC), }\end{array}$ \\
\hline Length, $\mathrm{m}$ & Width, m & Depth, m & \multirow{6}{*}{0.4} & 6 & 12 \\
\hline \multirow{5}{*}{1.0} & \multirow{5}{*}{0.5} & \multirow{5}{*}{1.0} & & 9 & 20 \\
\hline & & & & 12.5 & 25 \\
\hline & & & & 15 & 35 \\
\hline & & & & 20 & 45 \\
\hline & & & & 25 & 60 \\
\hline \multirow{6}{*}{1.0} & \multirow{6}{*}{0.5} & \multirow{6}{*}{1.0} & \multirow{6}{*}{0.5} & 6 & 17 \\
\hline & & & & 9 & 26 \\
\hline & & & & 12.5 & 37 \\
\hline & & & & 15 & 50 \\
\hline & & & & 20 & 65 \\
\hline & & & & 25 & 72 \\
\hline \multirow{6}{*}{1.0} & \multirow{6}{*}{0.5} & \multirow{6}{*}{1.0} & \multirow{6}{*}{0.7} & 6 & 20 \\
\hline & & & & 9 & 30 \\
\hline & & & & 12.5 & 46 \\
\hline & & & & 15 & 51 \\
\hline & & & & 20 & 70 \\
\hline & & & & 25 & 80 \\
\hline
\end{tabular}

oxygen transfer is influenced by the dispersion and coalescence characteristics produced through turbulent recirculation patterns existing in the basin.

In an unsaturated liquid, the volume of a gas bubble rising toward the free surface can vary through the effects of two opposing influences [2]. Because of the concentration difference between the bulk fluid and liquid film surrounding the bubble, there is a continued exchange from the bubble to the liquid and this dissolution process produces a decrease in mass of the bubble. At the same time, however, the decrease in hydrostatic pressure experienced with the bubble ascension affects expansion.

In the batch operation, one fluid (the gas phase in this case) is continuously passed through a basin that contains a uniform distribution of a second fluid (liquid phase). The liquid is retained within the reactor and is assumed "well- mixed". The oxygen content in the gaseous in gaseous phase is dependent on both bubble residence time and vertical position $[4,7]$.

Air flowrate influences on the system by means of different ways; the first one is the increasing the flowrate of air per specific volume of water boosts 


\section{Al-Rafidain engineering $\quad$ Vo. $14 \quad$ No. $1 \quad 2006$}

the amount of bubble released in this volume which accordingly leads to increase the attached surface area between the bubbles and water and then to raise the oxygen transfer rate. The second impact of this factor may result due to the escalating of the agitation degree of the system, which actually leads to further break up of large bubbles and to increase the transfer efficiency. The third influence of air flowrate may be explained by the effect of enhance the mixing and then the bubbles pattern within the tank. At relatively slight air flowrate, mild degree of turbulence in the water is produce, and the bubble columns took an almost direct path to the surface. When airflow rate increased, current patterns developed that forced bubbles to take longer paths to the surface. With the considerable amount of the air, strong downward bubble movement may be cause and then a general increasing in bubble residence time is caused resulting a longer time of bubble-water contact. Similar results also recorded by [7, 9, and, 10]

In figure 3 , the oxygen transfer capacity is plotted as a function of aerator submergence, at different airflow rates. As shown in the figure the factor has positive effects on oxygen transfer capacity. If the airflow rate is kept constant, the oxygen transfer is directly proportional to the aerator submergence. This result can be explained by the effect of the elongation of the path of bubbles due to increase aerator submerges. Other researchers also record similar notes $[9,10,13$, and, 16].

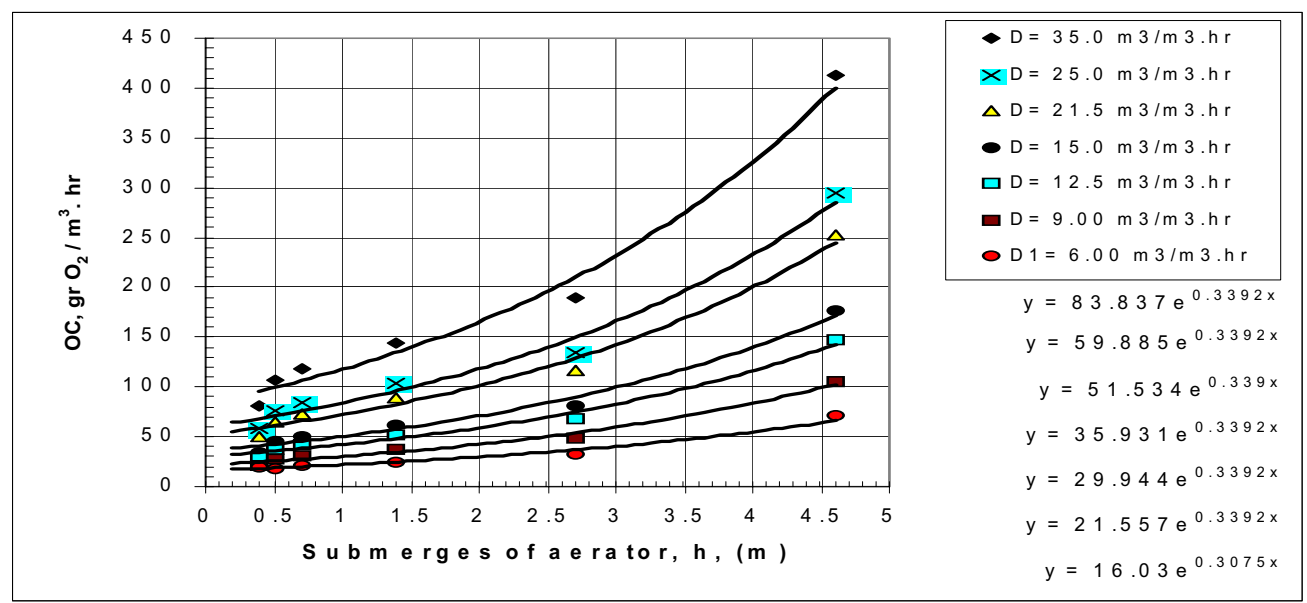

Fig (3): Effect of the level of aerator submerges (h) on the oxygenation capacity (OC) of the system at different specific air flowrate (D). [3, 6, 11-13]

However, figures 1, 3 can be used for the designer or engineer in estimating air requirements as well as evaluating the optimum diffuser submergence. Typically, influent and

effluent BOD are known or assumed, and, after selection of clarifier and aeration tank loadings , the oxygen transfer per day per unit volume of aeration tank 
become fixed and may be readily determined or estimated. A plot that expresses oxygen absorption at various rates may be used directly in the determination of optimum depth as well as volumetric air requirement.

In figure 4, another parameter is tested i.e.: oxygen transfer efficiency (E) This parameter physically represents the amount of oxygen transferred to the bulk solution by passing one meter cubic of air throughout the water and can be mathematically expressed by dividing the oxygenation capacity of the system on volumetric airflow rate passed through it.

$$
E=\frac{O C\left(\mathrm{grO}_{2} / \mathrm{m}^{3} \text { water } . h r\right)}{D\left(m^{3} \text { air } / m^{3} \text { water } . h r\right)}
$$

Where:

$E$ : oxygenation efficiency of the system, $\left(\mathrm{grO}_{2} / \mathrm{m}^{3}\right.$ air $)$.

The oxygenation efficiency parameter is very useful since it actually reflect how much gram of oxygen will be transferred to the bulk solution and absorbed in it by passing one meter cubic of air, i.e. oxygen / air ratio.

As well understand, this ratio is also depend on these parameters which control the normal oxygenation capacity of the system, i.e. airflow rate and, aerator submergence. However, drawn this factor directly with volumetric airflow rates give a definite horizontal line since the parameter itself is already calculated by dividing the oxygenation capacity of the system to the volumetric airflow rate passed, see figure 4.

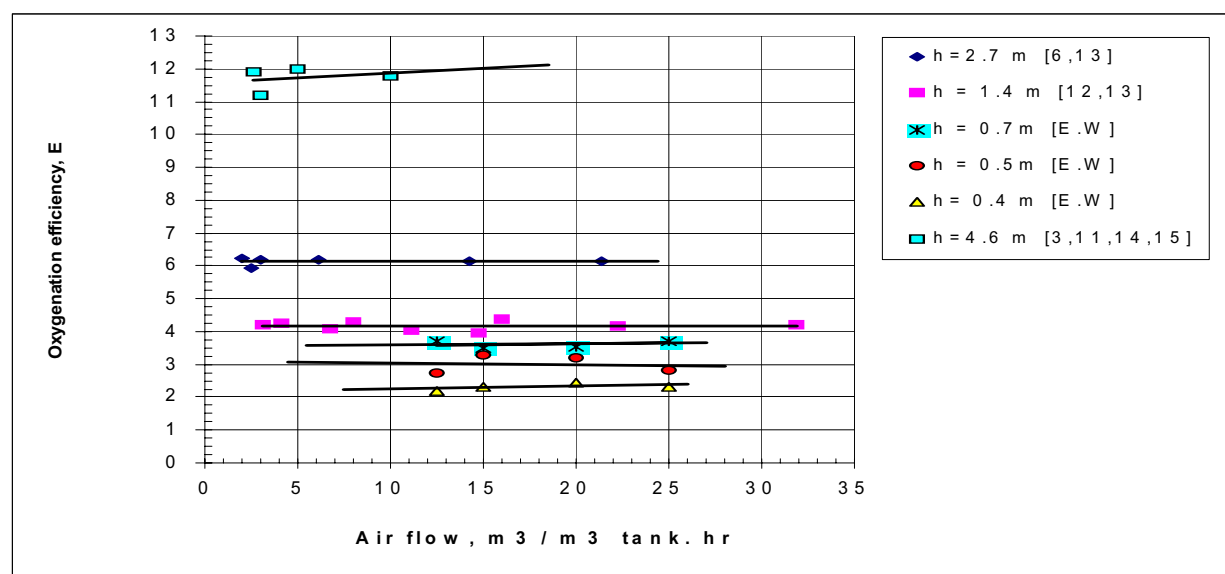

Fig (4): Effect of air flowrate (D) on the oxygenation efficiency of the system at different (h) values. E.W: experimental work 


\section{$\begin{array}{llll}\text { Al-Rafidain engineering } & \text { Vo. } 14 & \text { No. } 1 & 2006\end{array}$}

In figure 5, the oxygen efficiency (E) is drawn as a function of the aerator submergence. As shown in the figure, increasing aerator submergence significantly increases the amount of oxygen transferred by the one meter of air, i.e. oxygen / air ratio. At the small level of the aerator submergence, the ratio is low, with escalating the depth the ratio is increase gradually. The correlation, which controls this relationship, is linear. This curve and its kindliness can be explained by the effect of the aerator submergence on the actual oxygenation capacity. With increasing the depth, the pattern bubbles released is increases and then its probability to absorb in the bulk solution is raise. Some researchers [12] also record similar results.

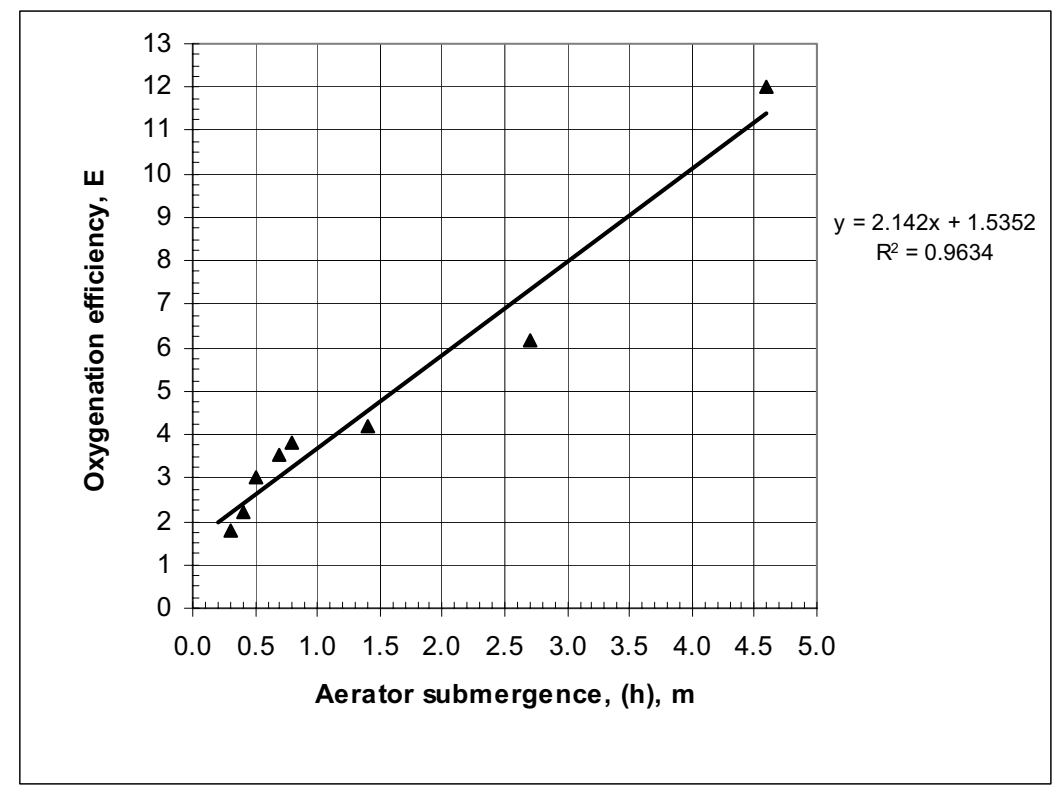

Fig (5): Effect of aerator submergence (h) on the oxygenation efficiency (E), at various air flowrate (D). [3,

\section{$6,11-15]$}

However, figure 5 is very useful in the calculation purpose since it can give the ratio of air that translate to the solution and transformed to oxygen. In the design, the actual amount of needed oxygen is known; from it and the curve, we can select the required depth of water and then the aerator submergence. After that, calculate the required airflow rate that should be applied.

\section{Conclusions:}

1. At fixed water depth and aerator submergence, increasing airflow rate showed an increase in percentage oxygen absorption and transfer capability for all tank depths and air rates tested.

2. The equation that controls the relationship between the airflow rates and oxygen transfer capacity is linear. The slopes of the equations are varying depending on the level of aerator submergence. At the depth of aerator ranging between $(0.4-4.6 \mathrm{~m})$, the slopes of the equations are $(2.11-11.8)$ respectively. 


\section{Al-Ahmady: Effect of airflow rate and submergence of diffusers on oxygen.....}

3. Increasing the level of aerator submergence significantly increase the oxygen transfer capacity of the system. This effect can be explained by the influence of increasing the bubbles paths and its detention time in the tank.

4. The exponentional form of equation proved to be efficient in the expressing of the relationship between the aerator submergence and the oxygen transfer capacity at different rates of air discharge. At submergence of aerator of $4.6 \mathrm{~m}$ and, airflow rate of $6.0 \mathrm{~m}^{3}$ air $/ \mathrm{m}^{3}$ tank.hr the oxygen transfer capacity is $70 \mathrm{grO}_{2} / \mathrm{m}^{3}$ tank.hr. Increasing the

5. airflow rate to $35 \mathrm{~m}^{3}$ air $/ \mathrm{m}^{3}$ tank.hr, with the fix aerator submergence, raise the oxygen transfer capacity of the system to about $380 \mathrm{grO}_{2} / \mathrm{m}^{3}$ tank.hr.

6. Increasing the depth of diffuser significantly increase the oxygen transfer efficiency of the system. The equation, which controls this relationship, is linear. At $0.4 \mathrm{~m}$ submergence, the oxygen transfer efficiency is 1.8 whereas; the transfer efficiency is rising to about 11.5 at a depth of diffuser equal to $4.6 \mathrm{~m}$.

\section{References}

1. American Society of Civil Engineering, "Wastewater Treatment Plant Design" WPCF Manual of Practice No. 8, ASCE Manual on Engineering Practice No. 36, Lancaster Press, Inc. Lancaster, Pa., USA, Third edition, Chapter 14, (Activated Sludge), 1991.

2. American Water Works Association, "Water Quality and Treatment" A Hand Book of Community Water Supplies, McGraw-Hill Handbooks, USA, Fifth edition, Chapter 5, (Air Stripping and Aeration), 2000.

3. Boyle W. C.; Craven A.; Danely W.; and Riech M., "Oxygen Transfer Studies at the Madison Metropolitan Sewerage District Facilities" Risk Reduction Engineering Laboratory, Office of research and Division, US. EPA, Cincinnati, Ohio, 45268, 1996.

4. Groves K.P. et al, "Evaluation of Oxygen Transfer Efficiency and Alpha Factor on a Variety of Diffused Aeration Systems", Water Environmental Research, 64, (5), 1992.

5. Kalinske A. A.; Lash L. D. and Shell G. L. "Cobalt Interference in the Non-Steady State Clean Water Test", Water and Sewage Works, 120 (54), 1973.

6. Khudenko B. M.; Shprit E. A., "Wastewater Aeration", Publishing House Stroyizdat, Moscow, 1973, (In Russian).

7. Lioyed E; David T.R; and Jermo D. W. "Testing and Data Analysis of Diffused Aeration Equipment", J. Water Pollution Control Fed., 51 (10).

8. Metcalf \& Eddy, "Wastewater Engineering" $4^{\text {th }}$ edition, Tata McGraw Hill Edition, New Delhi, 2003.

9. Michael B. L. and Ronald N. S. "Subsurface Aeration Evaluation", J. Water Pollution Control Fed., 51 (10), 1979.

10. Peter D. and Mark F., "Estimating Oxygen Transfer KLa, SOTE and Airflow Rate Requirements In Fine Bubble Diffused Air Systems", Water Environment Federation, WEFTEQ, 2001.

11. Richard C. A.; Gordon B. Rattray; and Paul P. D., "Air Diffusion Unit" J. Water Pollution Control Fed., 46 (5), 1974 
12. Shifrin S. M. and Mishukov B. G., "Treatment of Wastewater for Dairy Industry", Publishing House Stroyizdat, Moscow, 1972, (In Russian).

13. Suschka J., "Oxygenation in Aeration Tanks", J. Water Pollution Control Fed., 43 (1), 1971

14. Warriner R. and Brenner R.C., "Oxygen Transfer Efficiency Surveys at the Jones Island Treatment Plants 1985-1988" Risk Reduction Engineering Laboratory, Office of research and Division, US. EPA, Cincinnati, Ohio, 45268, 1996.

15. Warriner R. and Brenner R.C., "Oxygen Transfer Efficiency Surveys at the South Shore Wastewater Treatment Plant 1985-1987" Risk Reduction Engineering Laboratory, Office of research and Division, US. EPA, Cincinnati, Ohio, 45268, 1996.

16. Water Environment Federation, "Aeration". WEF manual of Practice - MOP FD-13, ASCE Manuals and Reports on Engineering Practice No. 68. American Society of Civil Engineers. New York. 1996. 